\title{
Photoluminescence of Tellurium(IV) Chloride Complexes in Solution
}

\section{Hans Nikol and Arnd Vogler*}

Institut für Anorganische Chemie, Universität Regensburg, Universitätsstrasse 31, W-8400 Regensburg, Germany

Received November 11, 1992

We wish to describe and discuss our observations on the photoluminescence of $\mathrm{TeCl}_{5}$ - and $\mathrm{TeCl}_{6}{ }^{2-}$-in solution. While lowtemperature photoemissions of $\mathrm{TeCl}_{6}{ }^{2-}$ and related $\mathrm{Te}$ (IV) complexes in the solid state have been observed before, ${ }^{1-3}$ here we report for the first time luminescence from a simple compound of an element of group 16 under ambient conditions. Moreover, our results are of general importance with regard to the nature of excited states of $\mathrm{s}^{2}$ complexes. In recent years we observed the solution luminescence of complexes of the type $\mathrm{MCl}_{3}{ }^{n-}, \mathrm{MCl}_{4}{ }^{n-}$, and $\mathrm{MCl}_{6}{ }^{n-}$ with the $\mathrm{s}^{2}$ metal ions $\mathrm{Ge}^{2+}, \mathrm{Sn}^{2+}, \mathrm{Pb}^{2+}, \mathrm{Sb}^{3+}$, and $\mathrm{Bi}^{3+} .4 .5$ We developed a general concept in order to characterize the emitting sp excited states. The luminescence of $\mathrm{TeCl}_{5}{ }^{-}$is the first example of an emission from a pentacoordinate $s^{2}$ complex. Our findings serve to check the validity of our previous assumptions.

The absorption spectrum of $\mathrm{TeCl}_{6}{ }^{2-}$ in acetonitrile (Figure 1) agrees with that reported previously. ${ }^{6,7}$ The long-wavelength absorptions of this octahedral complex are assigned to sp transitions: A band ( ${ }^{1} \mathrm{~S}_{0} \rightarrow{ }^{3} \mathrm{P}_{1}$ or ${ }^{1} \mathrm{~A}_{1 \mathrm{~g}} \rightarrow{ }^{3} \mathrm{~T}_{1 \mathrm{u}}$ in $O_{h}$ symmetry), $\lambda_{\max }=407 \mathrm{~nm}(\mathrm{sh}), \epsilon=800 \mathrm{M}^{-1} \mathrm{~cm}^{-1}$, and $385 \mathrm{~nm}, \epsilon=1500$; $B$ band $\left({ }^{\prime} S_{0} \rightarrow{ }^{3} P_{2}\right.$ or $\left.{ }^{~} A_{1 g} \rightarrow{ }^{3} E_{u},{ }^{3} T_{2 u}\right), \lambda_{\max }=320 \mathrm{~nm}, \epsilon=2500$, $C$ band $\left({ }^{1} S_{0} \rightarrow{ }^{\prime} P_{1}\right.$ or $\left.{ }^{1} A_{1 \mathrm{~g}} \rightarrow{ }^{1} \mathbf{T}_{1 \mathrm{u}}\right), \lambda_{\max }=298 \mathrm{~nm}, \epsilon=7100$, $287 \mathrm{~nm}, \epsilon=8200$, and $273 \mathrm{~nm}, \epsilon=7300$. Upon dilution $\mathrm{TeCl}_{6}{ }^{2-}$ was converted to $\mathrm{TeCl}_{5},{ }^{-6}$ which exists as a discrete ion with a square-pyramidal structure even in the solid state $e^{8,9}$ in accord with the VSEPR model. ${ }^{10}$ The $\mathrm{A}$ band of $\mathrm{TeCl}_{5}-\left(\lambda_{\max }=291\right.$ $\mathrm{nm}, \epsilon=1600$ ) appears at much shorter wavelength compared to that of $\mathrm{TeCl}_{6}{ }^{2-} .6$ Addition of chloride to this dilute solution led to a complete recovery of the spectrum of $\mathrm{TeCl}_{6}{ }^{2-}$ (Figure 1). The isosbestic points which occur during the spectral variations indicate the presence of only two species, $\mathrm{TeCl}_{5}^{-}$and $\mathrm{TeCl}_{6}{ }^{2-}$. The equilibrium constant $\left(\mathrm{TeCl}_{5}{ }^{-}+\mathrm{Cl}^{-} \rightleftarrows \mathrm{TeCl}_{6}{ }^{2-}\right)$ was determined to be $K=1.5 \times 10^{2} \mathrm{M}^{-1}$.

$\mathrm{TeCl}_{6}{ }^{2-}$ in $\mathrm{CH}_{3} \mathrm{CN}$ shows a red emission at $\lambda_{\max }=603 \mathrm{~nm}$ with $\phi=1 \times 10^{-4}$ at $\lambda_{\text {exc }}=388 \mathrm{~nm}$ (Figure 2). The excitation spectrum matched the absorption spectrum rather well. The spectral features of $\mathrm{TeCl}_{6}{ }^{2-}$ in solution $\left(\lambda_{\max }\right.$ of the ${ }^{1} \mathrm{~S}_{0} \rightarrow{ }^{3} \mathrm{P}_{1}$ transition in absorption and emission, Stokes shift $\Delta E=9400 \mathrm{~cm}^{-1}$ ) are quite similar to those of $\mathrm{TeCl}_{6}{ }^{2-}$ in the solid state (emission: $\lambda_{\max }$ $=632 \mathrm{~nm}$ at $\left.150 \mathrm{~K} ; \Delta E=10100 \mathrm{~cm}^{-1}\right) .^{2}$ In analogy to other $s^{2}$ complexes and in accord with results on $\mathrm{TeCl}_{6}{ }^{2-}$ in the solid state, the emission of $\mathrm{TeCl}_{6}{ }^{2-}$ in solution is assumed to originate from the metal-centered sp excited state ${ }^{3} \mathrm{P}_{1}\left({ }^{3} \mathrm{~T}_{14}\right.$ in $O_{h}$ symmetry) which undergoes a moderate excited-state distortion.

$\mathrm{TeCl}_{5}-$ in $\mathrm{CH}_{3} \mathrm{CN}$ shows a green luminescence at $\lambda_{\max }=538$ nm with $\phi=8 \times 10^{-3}$ at $\lambda_{\text {exc }}=280 \mathrm{~nm}$ (Figure 2). The excitation spectrum agreed with the absorption spectrum. The emitting excited state is certainly again the sp triplet ${ }^{3} \mathrm{P}_{1}$. However, the

(1) Wernicke, R.; Kupka, H.; Ensslin, W.; Schmidtke, H.-H. Chem. Phys. $1980,47,235$.

(2) Meidenbauer, K.; Gliemann, G. Z. Naturforsch. 1988, 43a, 555

(3) Schmidtke, H.-H.: Diehl, M.; Degen, J. J. Phys. Chem. 1992, 96, 3605.

(4) Nikol, H.; Vogler, A. J. Am. Chem. Soc. 1991, 113, 8988.

(5) Nikol, H.; Becht, A.; Vogler, A. Inorg. Chem. 1992, 31, 3277

(6) Stufkens, D. J. Recl. Trav. Chim. 1970, 89, 1185.

(7) Couch, D. A.; Wilkins, C. J.; Rossman, G. R.;Gray, H. B. J. Am. Chem Soc. $1970,92,307$

(8) Schönherr. T. Z. Naturforsch. 1988, 43b, 159.

(9) Ozin, G. A.; Vander Voet, A. J. Mol. Struct. 1972, 13, 435.

(10) (a) Gillespie, R. J.; Nyholm, R. S. Q. Rev. Chem. Soc. 1957, 11, 339. (b) Gillespie, R. J. Molecular Geometry; Van Nostrand Reinhold: London, 1972. (c) Gillespie, R. J.: Hargittai, 1. The VSEPR Model of Molecular Geometry; Allyn and Bacon: Boston, MA, 1991.

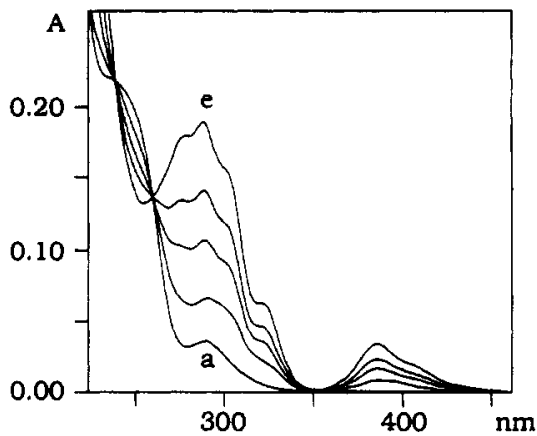

Figure 1. Electronic absorption spectra of $\left[\mathrm{NBu}_{4}\right]\left[\mathrm{TeCl}_{5}\right]$ in acetonitrile at room temperature $\left(1-\mathrm{cm}\right.$ cell). Absorption: $2.18 \times 10^{-5} \mathrm{M}$ without $\mathrm{NBu}_{4} \mathrm{Cl}$ (a) and in the presence of $7.08 \times 10^{-4}, 1.39 \times 10^{-3}, 2.08 \times 10^{-3}$, and $4.14 \times 10^{-3} \mathrm{M}$ (e) $\mathrm{NBu}_{4} \mathrm{Cl}$.

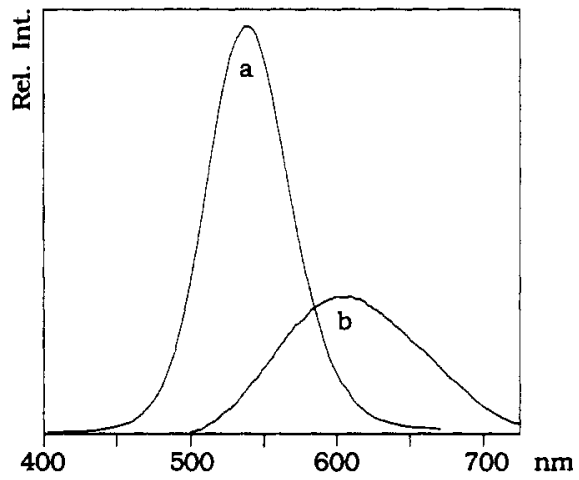

Figure 2. Emission spectra of $\left[\mathrm{NBu}_{4}\right]\left[\mathrm{TeCl}_{5}\right]\left(c=2.18 \times 10^{-5} \mathrm{M}, \lambda_{\text {exc }}\right.$ $=280 \mathrm{~nm}(\mathrm{a}))$ and $\left[\mathrm{NBu}_{4}\right]_{2}\left[\mathrm{TeCl}_{6}\right]\left(c=1.58 \times 10^{-4} \mathrm{M}, \lambda_{\mathrm{exc}}=400 \mathrm{~nm}\right.$ (b)) in acetonitrile at room temperature.

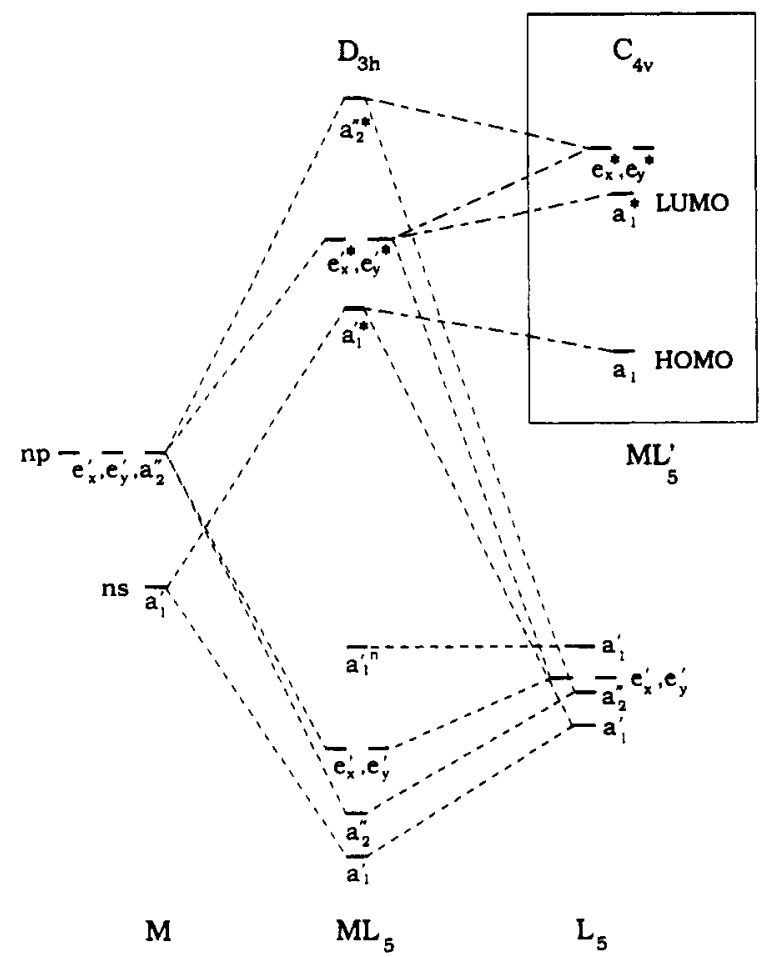

Figure 3. Qualitative MO scheme (Walsh diagram) of a trigonalbipyramidal complex $\left(D_{3 h}\right)$ and its distortion to a square-pyramidal structure $\left(C_{4}\right)$. The $\pi$-orbitals of the ligands are omitted. 
Stokes shift of the ${ }^{1} S_{0} \leftrightarrow{ }^{3} P_{1}$ transition $\left(\Delta E=15700 \mathrm{~cm}^{-1}\right)$ is much larger than that of $\mathrm{TeCl}_{6}{ }^{2-}$. Accordingly, $\mathrm{TeCl}_{5}$ - undergoes a much larger structural rearrangement in the excited state compared to $\mathrm{TeCl}_{6}{ }^{2-}$.

$\mathrm{TeCl}_{5}{ }^{-}$might be expected to have a trigonal-bipyramidal ground state structure $\left(D_{3 h}\right)$. However, the $\mathrm{s}^{2}$ electron pair would then occupy a strongly antibonding $a_{1}{ }^{\prime *}$ orbital (Figure 3 ). As a consequence, a distortion to a square-pyramidal structure $\left(C_{4 v}\right)$ takes place, because it is associated with an sp hybridization which lowers the energy of $\mathrm{TeCl}_{5}-$ by configuration interaction of the $a_{1}$ orbitals (Figure 3). ${ }^{11}$ The HOMO is thus stabilized and becomes stereochemically active as a lone pair in agreement with the VSEPR model.

In the $a_{1} a_{1}{ }^{*}$ sp excited state this stabilization of $\mathrm{TeCl}_{5}{ }^{-}$is lost because the $a_{1}$ * orbital becomes now the HOMO. We suggest that the complex relaxes then to the stereochemically less

(11) Albright, T. A.; Burdett, J. K.; Whangbo, M.-H. Orbital Interactions in Chemistry; Wiley: New York, 1985. demanding trigonal-bipyramidal structure. Such a geometrical change is in accordance with the large Stokes shift observed for $\mathrm{TeCl}_{5}{ }^{-}$. This explanation is consistent with a general concept which has been developed to characterize the emitting sp excited states of $\mathrm{s}^{2}$ complexes. ${ }^{12,13}$

The octahedral structure of $\mathrm{TeCl}_{6}{ }^{2-14}$ is an exception from the VSEPR rules possibly because there is no space left for a distortion which must provide an open coordination site for the lone pair. In the case of $\mathrm{TeCl}_{5}-$ the lower coordination number facilitates a distortion in accord with the VSEPR model.

Acknowledgment. Support of this research by the BMFT is gratefully acknowledged.

(12) Vogler, A.; Nikol, H. Pure Appl. Chem. 1992, 64, 1311.

(13) Vogler, A.; Nikol, H. Comments Inorg. Chem. 1993, 14, 245.

(14) A slight dynamic ground-state distortion seems to occur in the solid state: Abriel, W. Z. Naturforsch. 1987, 42b, 1273. 